\title{
EFFECT OF INDUSTRY 4.0 ON REDUCING THE OCCUPATIONAL FATIGUE DOWNTIME USING CONSTRAINED DATA MINING CLUSTERING AIDED WITH RULE INDUCTION
}

\author{
SAMIA ELATTAR ${ }^{1,2} \&$ AHMED M. ABED ${ }^{3}$ \\ ${ }^{I}$ Department of Industrial and Systems Engineering, College of Engineering, Princess Nourah bint Abdulrahman University, \\ Riyadh, Saudi Arabia
}

${ }^{2}$ Department of Industrial Engineering, Alexandria Higher Institute of Engineering and Technology (AIET), Alexandria, Egypt

${ }^{3}$ Department of Industrial Engineering, Zagazig University, Zagazig, Egypt

ABSTRACT
The Occupational fatigue represents a major threat for the continuation of the work and appears two types of
Lean's waste, such as defects and downtimes. The effect of Occupational fatigue that must be faced varies
according to the work volume, the number of employees, the nature of the product, and other various factors.
The Industry 4.0 works on waste's mitigation to achieve productivity competitiveness' for enterprises that
establish countries renaissance and help to classify these enterprises according to behavioral factors to be ready
to mitigate all negative effects. This paper identifies the major factors that profile the losses of a fatal
occupational fatigue to face the defects and downtime. The CAPMAS registered occupational fatigue that
causes losses and their characteristics in some industrial cities. The fatal occupational fatigue (FOF) was
registered that had been in comparison to a similar pattern of (none) fatal fatigue (NFOF) in the identical year
The fatigue workers of body were a head, terminals, or internal organs. The main purpose of the paper is to
draw attention to join the occupational fatigue to the list of waste, which dealt with Lean.
KEYWORDS: Ergonomics Site; Injuries Preventive; Lean Wastes; DOE; Six-Sigma

Received: Nov 18, 2020; Accepted: Dec 09, 2020; Published: Dec 23, 2020; Paper Id.: IJMPERDDEC202052

\section{INTRODUCTION}

This paper draw attention to determine the industry 4.0 level in the enterprises without extra financial burdens and achieve continuity without losses. The industry 4.0 is an important requirement to allow enterprise loans to be granted to ensure their viability and insurance. Industry 4.0 advocates to equipment and production tools' usability and give a chance of basing on the IOT (Internet of things) technique to classify a large behavioural datasets and deduce a profile curve easy to reduce the occupational effects. This paper help in finding an answer to core question, what is the industry 4.0 level, which face the occupational fatigue without extra financial burdens. The occupational fatigue back to worker behaviour and nature of production, which different from one to another. Therefore, using constrained clustering to classify workers and determine the industry 4.0 level contribution. The dependencies of occupational fatigue is a crucial issue in safety sites. The classification makes a chance to transition a worker from cluster to another according his behaviour and some other related factors. The error in classification of traditional methods of is not suitable in this situation because of the lack of historical data. Therefore, literature addresses this 
challenge using two stages of data mining techniques by clustering the worker functional behaviour then classifying the newly added ones into these clusters according to their behaviour. The level of industry 4.0 implementation according production type and worker skills is classified using constrains' K-means algorithm aided with rule induction that generate the criteria tied each cluster with similar characteristic behaviour's profiles. The constrained data mining aided with rule induction helps in integrating of using industry 4.0 without extra financial burdens. One Egyptian worker feels with fatigue every $2 \mathrm{hrs}$ because of bad habits at work because they disregard the principles of lean cultures in their activities implementation (Egyptian Commission, 2019). Research on the causes of FOF needed in order to improve proactive actions prelude to prevent these negative effects of Occupational fatigue based on the scientific evidence [12]. An extensive variety of individual and word related components, alongside age, sexual orientation, instructional stage, word related notoriety, or ways of life, have been seen to be identified with the misfortunes of enduring a FOF) as understood from many researchers [1,9,14 and 15]. In trendy, few etiological studies have been completed on this concern [8], especially thinking of the complexity of variables which play a position in the incidence of occupational fatigue and which could regulate the chance of a fatigue result. Elements associated with the occurrence of a (FOF) may additionally act at numerous tiers similarly to employee's environmental situations, including the administrative centre (proximal environmental conditions), the paintings surroundings (paintings business enterprise and situations) or maybe the social and political degrees (employment or monetary regulations) [5 and 13]. Epidemiological researches of (FOF) have a concern, because that it is able to assist to improve the behavioural knowledge of factors and mechanisms, which growth the chance of (FOF). This paper is useful in determining the preventive measures effectively [3] beside increasing the consciousness of the size of this issue among broad communications, policymakers and the general public all in all [4] and [15] to nation renaissance without additional weights. The point of this investigation is to break down the function of a few word related components that make misfortunes, need supporting by means of industry 4.0 revolution, With a view to providing further proof for the layout and implementation of preventive measures in the occupational setting 

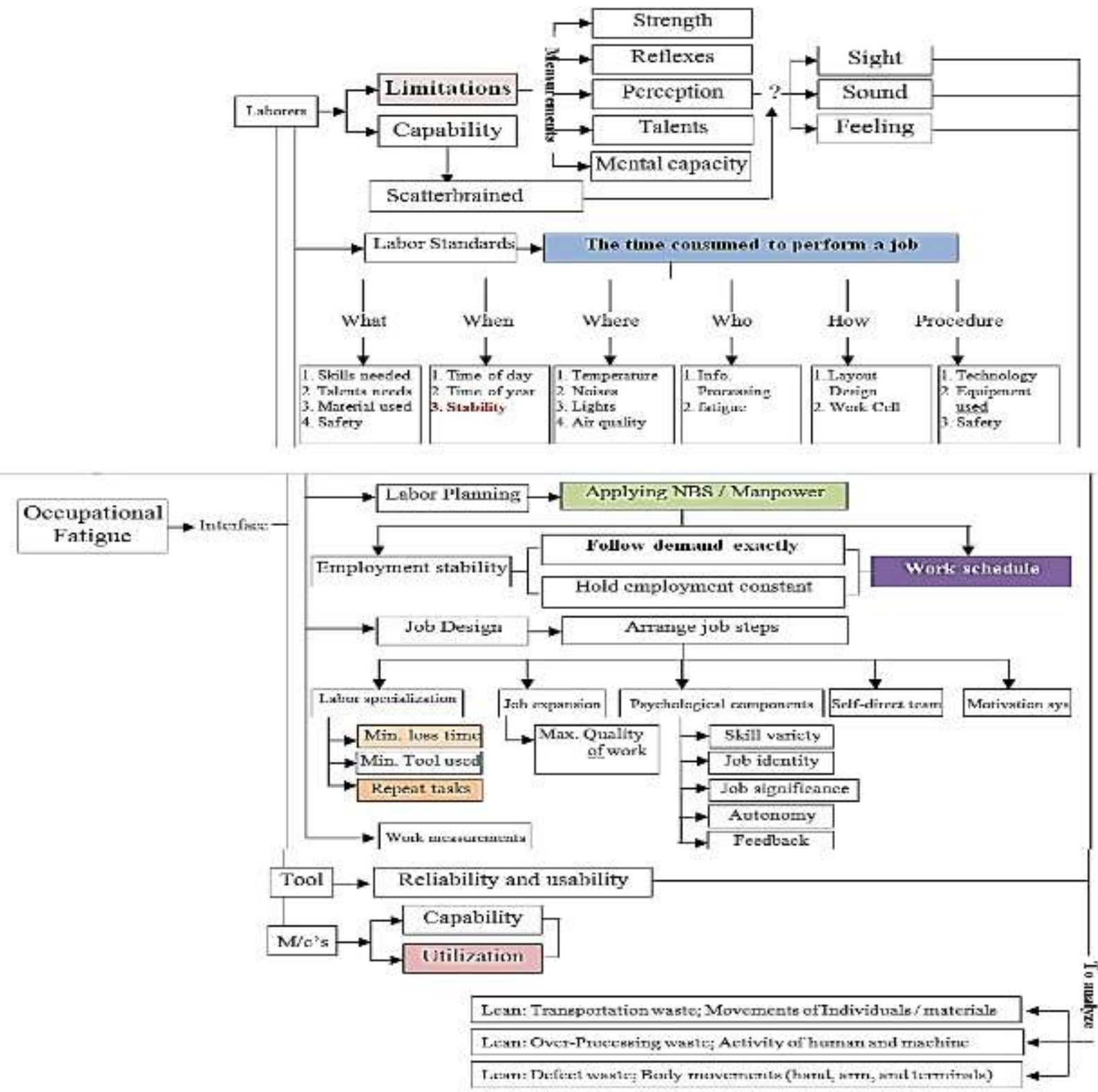

Figure 1: The database of machine / labor interaction factors

\section{PROBLEM DESCRIPTIVE AND ITS RELATIONSHIP}

In this paper, three types of similarity measures are used for identifying the related tuples via two sequential phases. The first based on the behaviour associations (both positive, negative and non-value effect) found by association mining. Clustering is the partitioning of workers' behaviours into several identical clusters and assigning a large number of observed workers skills. Many clustering techniques such as K-means is trendy clustering algorithms used [18] that are represented by the mean value of the observed data values belonging to each of them to minimize the Euclidean distances totally between nearest cluster centre. $\boldsymbol{d}(\boldsymbol{X} . \boldsymbol{Y})=\sqrt{\sum_{i=1}^{n}\left(\boldsymbol{x}_{\boldsymbol{i}}-\boldsymbol{y}_{\boldsymbol{i}}\right)^{2}}$, where the Cost function of K-means is mentioned below

$$
C(U)=\operatorname{argmin} \sum_{i=1}^{k} \sum_{j=1}^{n}\left(\left\|x_{j}-\mu_{i}\right\|\right)^{2}
$$


Where, $\mu_{\mathrm{i}} \mathrm{n}$ is the number of data points in $\mathrm{i}^{\text {th }}$ cluster. $\mathrm{K}$ is the number of cluster centers. The multi-variate regression models tested on the selected clusters within the tuples that are similar with respect to their weekly losses profiles. The second is based on identifying the economical level of having the industry 4.0 equipment's. Based on these types of classification measures, three different tuples schemes are extracts to determine the related worker skills tuples. The first tuple profile is a heuristic method based on the worker skills associations. The second tuple profile based on a clustering approach by using the constrained k-means algorithm in which the workers' skill used for computing the similarity measure. The third profile based on the constrained clustering that aided by rule induction powerful in which both worker skills associations and the losses profiles used for identifying worker tuples.

\subsection{Associated Heuristic clustering}

Associated mining technique is an opportunity of deriving and concluding the employee's talents as opposed to conventional strategies. Therefore, the subsequent heuristic approach devised to decide the related worker abilities organizations inside the following steps:

- Create a worker's talents list by sorting all by their losses gained due to NFOF and observed FOF in descending order.

- $\quad$ Select the focal pinnacle of the list.

- Select up to two positively associated workers' skill with the cluster focal worker skills from the list by searching the list by track.

- Select up to two negatively associated worker skills with the focal cluster skills from the list by searching the list from down to up.

- Remove the worker's clustering focal and the associated one from the list to form the associated tuple.

- If there is no worker skills in the list, then stop. Otherwise, go to Step 2.

This paper adopts the inductive getting to know that maximum commonly used in actual-global applications and relatively speedy as compared to different techniques, such as AQ, CN2, and the more recent algorithm called RIPPER mechanism (Repeated Incremental Pruning to Produce Error Reduction), which have three stages processing building, optimizing, and trimming. This mechanism encourage to decision tree induction that is in contrast used to path to each leaf in a decision tree corresponds to a specific rule as shown in Figure 2. In this way, the rules learned should be of high accuracy. 


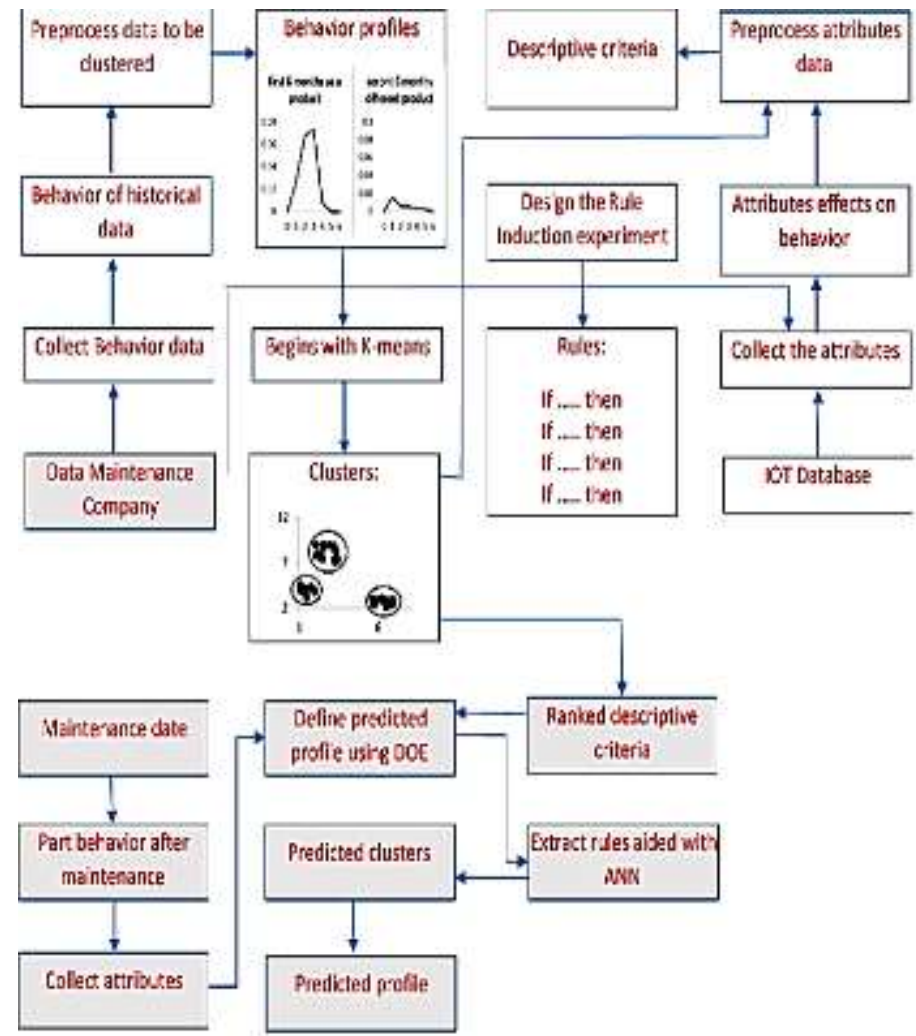

Figure 2: The proposed COFC technique

\section{THE PROPOSED CLASSIFICATION MODEL}

In this paper, the proposed framework is demonstrate interactive analyze visually to extract tuples and allow comparing themselves accuracy. Figure 2 illustrates the model, which begins with uploading the significant factors that effects on losses elimination via preparing the collected data and transforming the available observed data into a suitable form before clustering them into tuples of similar working profiles via aiding of rule-induction techniques to build a classification model rely on linking the descriptive attributes profiles. The classification model is used to predict the behavior profiles of the new worker or product rely on their descriptive attributes.

\subsection{Rule Induction Algorithm}

Learn a set using IF-Then rules for classification [Sequential covering]

Input:

IOT-D; a data set uploaded via observation and feed the internet of things class-labeled tuples controlled via IOT;

Sign-Fac-vals, the set of all significant factors and their possible values

Outputs:

A set of IF-THEN rules Method

(1) Rule-set= \{\} ; // initial of learned set rules in empty situation

(2) loop each class A do

(3) Repeat 
(4) Rule = Learn-one-rule(IOT-D,Sign-Fac-vals, A);

(5) Remove the covered tuples by induction Rule from IOT-D and save available data to analyse;

(6) Rule-set=Rule-set+Rule; // insert rule to rule set

(7) Until terminating condition;

(8) End-loop

(9) Return Rule-set;

The proposed model uses a different data pre-processing strategy than Fiordaliso's model [19], which divided the life span of all to the study horizon. The proposed model normalizes the technical specifications of the working into the relative specifications. Therefore, instead of using the part, it is replaced by the relative compared to the competing after maintaining actions. Such relative specifications of any product are affected by the introduction of new competing products into the working environment. Therefore, the proposed model divides the life span of the items into unequal periods. The use of this short period life cycles normalizes the life span of the working and coincide the relative specifications of the by considering the newly begins span, as illustrated in Figure 3.

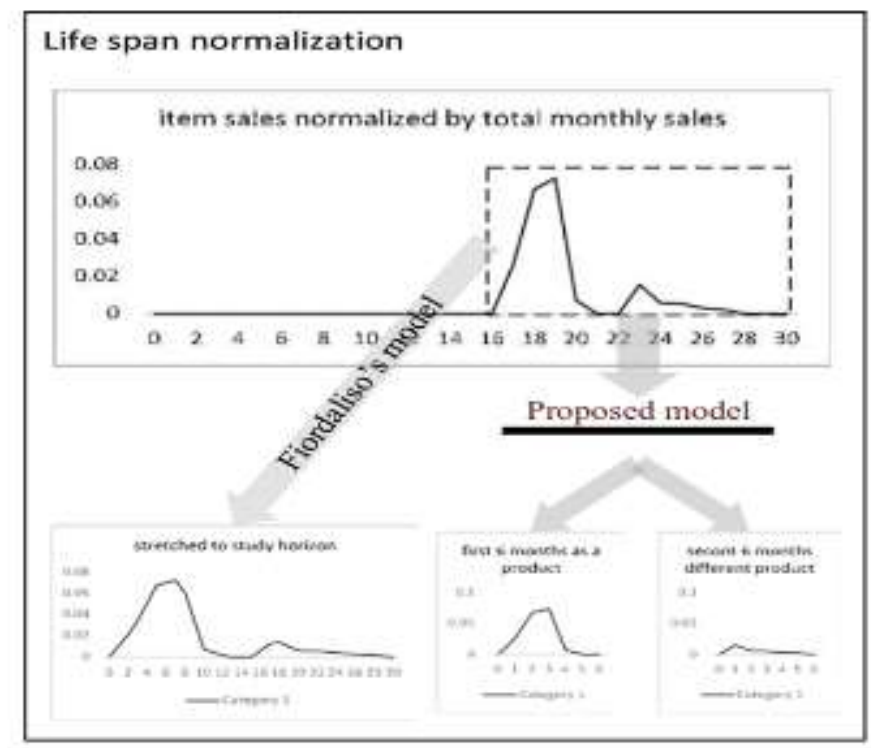

Figure 3: Worker and product scale lifetime

The constrained K-means

The using of category information is the easy way of discovering the related clusters similarities practically. K-means can be formulated as a mathematical program for clustering N-1 over a period of $\mathrm{t}$ in the following way. Given a IOT-D = $\left\{x_{i}\right\}_{i=1}^{m}$ of $\mathrm{n}$ points () in $\mathrm{R}^{t}$ and $\mathrm{k}$ desired clusters, the problem is to determine cluster focal point $\mathrm{C} 1, \mathrm{C} 2, \ldots, \mathrm{Ck}$ in $\mathrm{R}^{t}$ such that the sum of the squared distance between each point $\mathrm{xi}$ and its nearest cluster centre $\mathrm{Cl}$ is minimized as follow equ.1. This equation helps in removing the inner min operator in Equation 1 by introducing "assignment" factors $Y_{i, l} i=1 \ldots . . m . l=$ $1 \ldots \ldots \ldots k$. Note that $Y_{i . l}=1$ if data point $x_{i}$ is closest to centre $C_{l}$ (i.e. belongs to cluster 1) and zero otherwise.

$$
\min _{C_{1} \ldots . C_{k}} \sum_{i=1}^{m} \min _{l=1 \ldots k}\left(\frac{1}{2}\left\|x_{i}-C_{l}\right\|\right) \ldots
$$




$$
\underset{C . Y}{\operatorname{minimize}} \sum_{i=1}^{m} \sum_{l=1}^{k} Y_{i . l}\left(\frac{1}{2}\left\|x_{i}-C_{l}\right\|\right) \ldots .
$$

s.t. $\sum_{l=1}^{k} Y_{i . l}=1 . i=1 . \ldots . m$ where $Y_{i . l} \geq 0 . i=1 . \ldots . m . l=1 . \ldots . k$.

Notice that $\boldsymbol{n}$ items can be associated into $k$ with non-covering by utilizing $\boldsymbol{t}$ shift of losses to to figure the comparability measure in k-implies algorithm. The similitude measure for this situation is the Euclidian distance as previously mentioned, and found in the target capacity of Equation 2.

The essential plan to improve the conduct profile with supporting industry 4.0 in this kind of tuple is that the gatherings are made out of emphatically and the adversely related things. Now and again, least group size requirements forestall the problematic neighborhood arrangements of k-implies calculation; the calculation ready to identify the bunch habitats with as hardly any limitation infringement as could reasonably be expected. Lagrangian unwinding of the streamlining issue can conquer the infeasibility issue. Notice that the conditional IOT-D is utilized for the affiliation mining step and the obliged bunching is run on a different set of information, in which the thing properties can be presented.

\subsubsection{Determine Must-link Constraints.}

Apriori algorithm implements on IOT - D transactional data to generate item frequently (2-itemsets) with a minimum value to determine the tuples of must-link constraints i.e. $\{c=(i . j)\} i . j=1 \ldots . m$

\subsubsection{Determine Cannot-link Constraints.}

The indirect associated mining algorithm is implemented when IOT $-\boldsymbol{D}$ generates negative association tuples that determine the cannot-link constraints i.e. $\{c \neq(i . j)\} i . j=1 . \ldots . m$

\subsubsection{Create the Constrained Clustering.}

Generate clusters via following steps (A, B, and C) until the solution converges:

Cluster Assignment: Let $Y Y_{i . l}^{S}$ be a solution to Equation 3 of with $C_{l . s}$ fixed.

Cluster Update: Update $C_{l . s+1}$ as follows:

$$
C_{l . s+1}=\left\{\begin{array}{cc}
\frac{\sum_{i=1}^{m} Y_{i . l}^{s} x_{i}}{\sum_{i=1}^{m} Y_{i . l}^{S}} \text { if } \sum_{i=1}^{m} Y_{i . l}^{s}>0 \\
C_{l . s} & \text { otherwise }
\end{array} .\right.
$$

C. $s \leftarrow s+1$

The purpose here is clustering similar-focal point in terms of working behavior's profiles as a cluster center, which characterizes the studied behavior included in the cluster. The k-means algorithm achieves exclusive clusters and requires determining the desired number of clusters, which influences the quality of the partition and the efficiency of the rule induction (second stage of the classification system). The optimal number of clusters is estimated by minimizing the mean absolute error of the system's ability to forecast the losses of the validation items.

\section{PROBLEM STATEMENT}

The data of the study was obtained from the IOT-D of The CAPMAS (Central Agency for Public Mobilization and Statistics, Egyptian Commission, 2019), and collecting occupational fatigues registered in some of HR IOT-Ds for factories in 10th of Ramadan and El-Obour City in 2019 and 2020. Notification of (FOF and NFOF) is mandatory in Egypt for companies in new 
renaissance, and reports contain, for each losses at work, these causes are interacted together and have some common themes. The IOT-D have data on the fatigued laborer, on characteristics of work and company, on circumstances of the unfavorable occasion related to the weariness and on the nature and results of the weakness as outlined in "Fig. 3",all these IOT-Ds were manipulated via data mining concept. In 2019; 21,309 occupational fatigue causing at least 1 day of losses reported by companies at departments.

All $($ FOF) reported $(n=269)$, while NFOF $(n=1153)$ were considered within the test for this consider, and 300 genuine and slight fatigue as enrolled within the IOT-D were chosen haphazardly from the remaining records. Traumatic word related weariness, commuting word related weakness, and backslides of previous word related weakness were avoided "Fig .4" illustrates the main causes of fatigue happen and its percentage impact via enquiring random sample of workers in Egypt factories; this figure is discussed in sequential tables from (Table-1 to Table-3), the time of this study is continuous two years. (Table-1) illustrates the occupational variables in the Egypt Occupational Fatigue Notice Frame and chosen for this examination. The prompt circumstances of occasions driving to word related weakness (Table-2), such as component, presentation, and fatigued worker of body, were compared for (FOF) and (NFOF) with $X^{2}$ test. To survey the part of occupational variables, balanced chances proportions were gotten through (log)-regression analysis for factors in (Table-1). A work built from a immersed show selecting factors consequently in reverse, with a centrality level of 0.10 to exit. Importance of categories of chosen factors was advance tried with Wald test, and factors with most categories with $\mathrm{p}>0.10$ were taken out of the ultimate function.

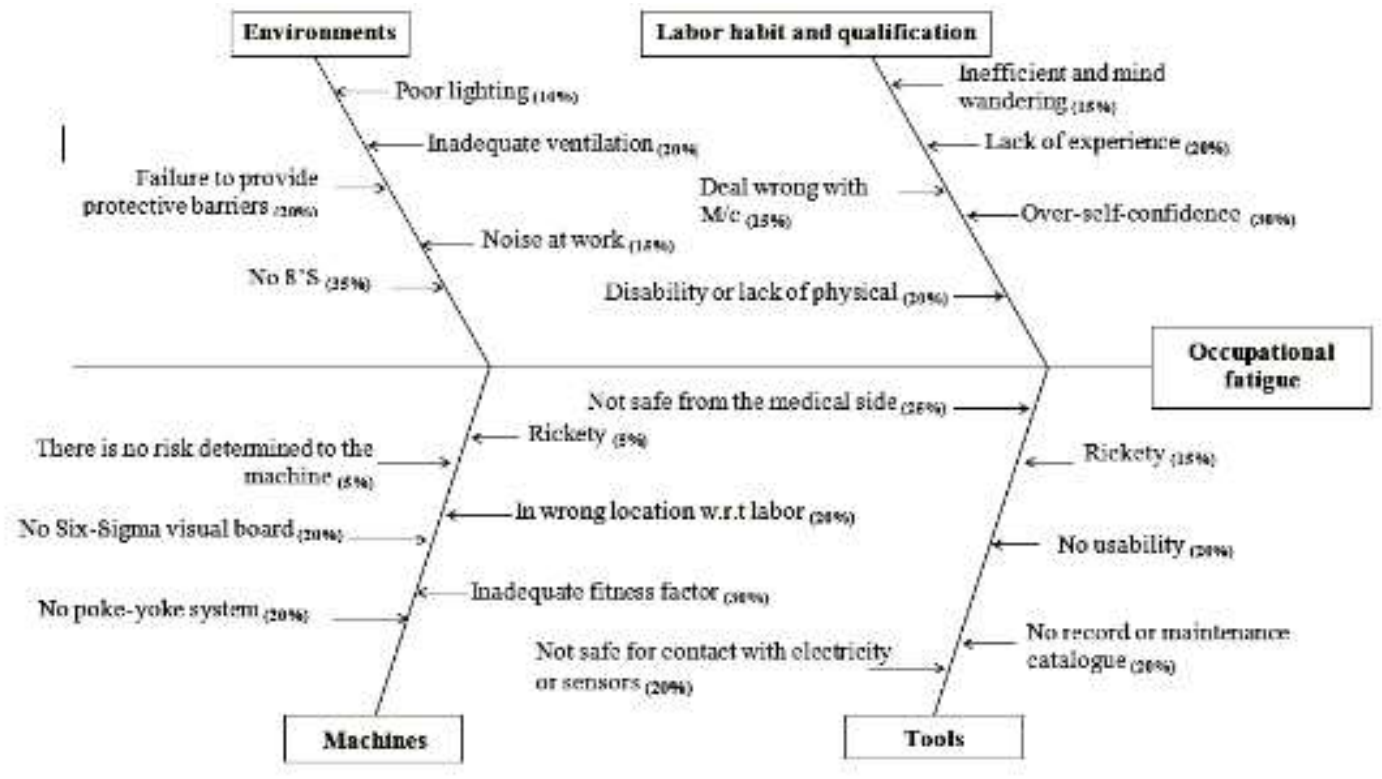

Fig. 4: Cause and effect diagram of occupational fatigue

\section{DATA MINING ANALYSIS METHODOLOGY (DATA SELECTION AND PRE-PROCESSING)}

This paper takes into account the dimension of the data used in this analysis to generate "Fig. 4" and filtered this data by three filters. The first is the time dimension filter, which ensure from modernisms and validity of data. The second is the content dimension filter, which ensure from data truest, completion and has strongly relation with the problem statements. The third dimension filter is the model, which give us the ability of good treatment for the data and present the results and conclusion. 


\subsection{The first Dimension (Time)}

This dimension can described as illustrated in "Fig. 5" to test the data validity and modernism before selection for analysis and can obtain it in time. The model divide into five area, (A) illustrates the doubt area of data, therefore no selection for data before stability area (B), this area represents a good selection area for analysis, after this area observes modernism and validity avalanching, but can use data before area (D), because in area (E) no data valid. The time between (t1) and (t2) based on save the data with its modernism, but the span between ( $\mathrm{t} 2$ ) and ( $\mathrm{t} 3$ ) depends on appearing new data expose the problem, the span between ( $\mathrm{t} 4)$ and $(\mathrm{t} 5)$ is very narrow, these boundaries are adjust statistically by expert of stakeholders using brainstorming.

\subsection{The Second Dimension (Truest Content)}

In this section, the researcher depends on collect data from multi-sources using questionnaires or interviews with random sample of workers in different sectors of manufacturing or services. Such as, the workers who need muscles fitness to implement their works. This filter helps us to select data that has consensuses of workers. This dimension interest in classify and make a group of workers according to their reputation, experience and culture. The truest content model as illustrated in "Fig. 4" is divided to four creditability sectors. The sector $\left(\mathrm{x}^{+}, \mathrm{y}^{+}\right)$represents the workers and HR IOT-Ds which have a data has strong relation with the problem and viable, the sector $\left(\mathrm{x}^{+}, \mathrm{y}-\right)$ represents the group of HR IOT-Ds and workers that have no relation with the problem, as illustrated by circle (E) and it abduced as circle (D). This paper based on data has more than one intersection between the circles in sector $\left(x^{+}, y^{+}\right)$with suitable weight (wx) in horizontal direction and weight (wy) in vertical direction. The data that collected from the group in circle (C) has large weights. As this think, the paper adjust the percentage values of the root causes that appeared in the "Fig. 4" and have direct impact on occupational fatigue and lead to more than 1 day of losses or causes down times.

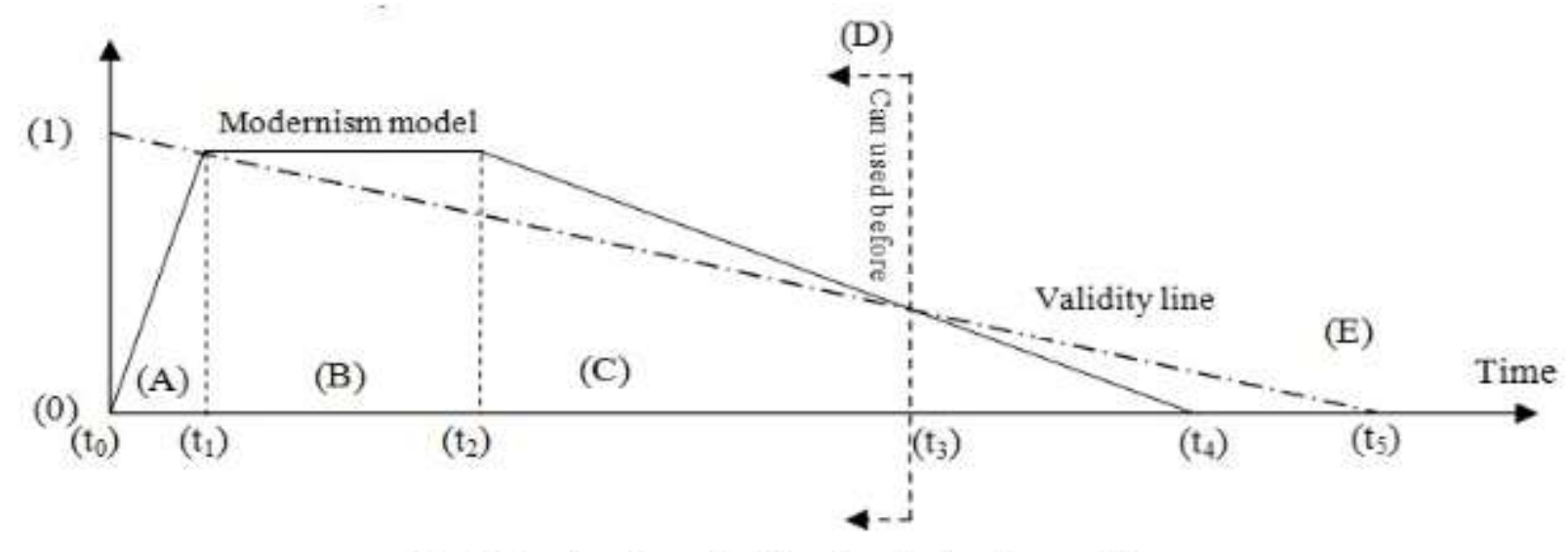

Fig. 5: The time dimension filter for selective data model

The next stage is transforming all selected and pre-Processing data for suitable IOT-D, but after using "Fig. 5" and "Fig. 6" models thinking to avoid any data inviable or has noises. The data appeared from (Table-1 to Table-3) is the data mining analysis results, which based on 1422 suitable data that led us to conclusion help in preventive the root causes of occupational fatigue or down times. Remember, the main objective of this paper is achieving the continuity of the productivity and reduce the negative feeling of workers, may be getting their loyalty and efforts.

\section{RULE INDUCTION}

After clustering the Occupational fatigue misfortunes information names such as $\boldsymbol{c l} \mathbf{1}, \boldsymbol{c l} \mathbf{2}, \ldots, \boldsymbol{c l} \boldsymbol{i}, \ldots, \boldsymbol{c l} \boldsymbol{k}$ representing the 
occupational fatigue downtime or defects profiles of the shaped tuples, are doled out to the found clusters. A preparing IOT-D for the classification calculation is built through the graphic qualities names. Each specialist is portrayed by the graphic traits as an input, whereas the cluster to which it has a place is considered as the yield. The rules-induction (RIPPER) utilized to extricate if-then Boolean rules from the preparing information set to supply a comprehensive understanding into the information and to anticipate the occupational fatigue downtime profiles of the unused based on their expressive properties. It is essential that the number of generated-rules is lower than the number of data-points within the preparing IOT-D, which the number of properties depicting each run the show is decreased.
1. If $\alpha 1=10$ then Cluster $=3$
2. If $\alpha 2>=9$ and $\alpha 3>=5$ then Cluster $=10$
3. If $\alpha 6=1$ and $\alpha 1<=6$ then Cluster $=1$
4. If $\alpha 4=5$ and $\alpha 5<=4$ then Cluster $=11$
5. If $\alpha 2=2$ then Cluster $=0$
6. If $\alpha 6=2$ and $\alpha 8=1$ and $\alpha 4<=4$ then Cluster $=2$
7. If $\alpha 2=7$ and $\alpha 7>=3$ and $\alpha 8<=3$ then Cluster $=2$
8. If $a 6=5$ then Cluster $=9$
9. If $\alpha 6=2$ and $\alpha 2<=6$ then Cluster $=13$
10. If $\alpha 1>=8$ and $\alpha 2>=9$ then Cluster $=12$
11. If $\alpha 2<=1$ then Cluster $=4$
12. $\alpha 1>=6$ and $\alpha 4<=3$ then Cluster $=5$
13. If $\alpha 1>=6$ and $\alpha 9>=5$ then Cluster $=5$
14. If $\alpha 8=5$ then Cluster $=6$
15. If $\alpha 1=1$ then Cluster $=7$
16. If $\alpha 2=3$ then Cluster $=8$
9 attributes from $\alpha 1$ to $\alpha 9$ to build rules
for example, $\alpha 1$ is price rank $\& \alpha 2$ is average discount
percentage and so on

\section{DATA MINING ANALYSIS RESULTS}

Industry 4.0 mediate to lessen the losses happened because of (FOF) or (NFOF). There are 1422 occupational fatigue considered. These incorporate (FOF: 269) and (NFOF: 1153). (Tables 1 and 2) outline a detailed distribution for the impact of various factors on losses to conclude the commitment level of industry 4.0. (Table-1) shows, more FOF than NFOF happened in men $(\mathrm{p}<0.009)$. Hence, they should be observed and upheld with agreeable innovation as pushed by industry 4.0. Furthermore, $(F F)$ laborers were more established than NFF ( $p<0.01$; that speaks to a direct pattern $=48.749, p<0.01)$. The vast majority of FOF happened in modern laborers (35.68\%), while the area of administrations was the principle area of monetary movement for NFOF (38.33\%) and $65 \%$ of FOF happened in organizations with medium scale at under 150 specialists ( $70 \%$ for NFOF), and $65 \%$ influenced manual laborers ( $86 \%$ NFOF).

$76 \%$ of FOF shows up in transitory laborers ( $54 \%$ for NFOF) and $68 \%$ were utilized not exactly half year ( $42 \%$ for NFOF). Somewhat more than a portion of FOF (61\%) shows up in the focal of the work move time, somewhere in the range of third and sixth hrs., versus half for NFOF ( for the linear $=12.61, \mathrm{p}<0.01$ ). The mean time of work for exhausted laborers was for FOF and NFOF around 4 years $(\mathrm{p}=0.36$ ). No patterns were noticed with respect to the event of FOF along the week 
however little on Tuesday and have a greatest incentive on ends of the week, neither for NFOF. 15\% of FOF shows up on Saturday and $42 \%$ on Thursday, while circulation of NFOF on the week differed from $28 \%$ on Sunday, $16 \%$ on Tuesday and $23 \%$ on ends of the week. In excess of a fourth of FOF $(28 \%)$ happened in atypical work environments $(11 \%$ for NFOF, $<<$ $0.01)$ and $30 \%$ while playing out an atypical work $(14 \%$ for NFOF, $\mathrm{p}<0.01)$. (Table-2) outlines that conditions of occasions (included specialist, instrument and exhausted laborer of body) contrasted with convey the business 4.0 commitment level. Most FOF were created by overstrains, with $22 \%$ of deadly exhaustion and Strike, with $42 \%$ (34\% and 42\% for NFOF, individually), "general" (as finished up from the IOT-D) specialists (31\% versus half for NFOF), or Worker self-assurance ( $28 \%$ versus $26 \%$ for NFOF, separately). What's more, the NFOF of inadequate and apparatuses, wrong gadget area speaks to $28 \%$ and $26 \%$ individually. FOF influenced frequently a few specialists of the body (84\%) and NFOF influenced chiefly appendages (65\%). When contrasted with NFOF, more FOF that created by rationale causes or "other" (as enlisted in the IOT-D) causes $(\mathrm{p} \leq 0.01)$. Included specialists in FOF were much of the time height, transport gadgets, abuse of hardware and climate conditions $(\mathrm{p}<0.01)$, and the more every now and again exhausted laborers of body were inward organs, terminals or head $(\mathrm{p}<0.01)$. Then again, personal times misfortunes created by overstrain, by devices or gadgets, or influencing trunk or appendages that essentially identified with NFOF $(\mathrm{p} \leq 0.01)$.

(Table-3) shows examination results, with all NFOF thought about by and large as controls. Male sexual orientation, expanding age, atypical work environment, atypical employment assignments, working in occupation shop areas, expanding hour of the work move and transitory agreement are identified with a lethal outcome after occupational fatigue.

Table 1: (Industry 4.0) priority implementation for

Occupational characteristics in a sample of workers suffering occupational fatigue in Egypt, $2019(\mathrm{n}=1422)^{a}$. [7] [17]

\begin{tabular}{|c|c|c|c|}
\hline & $\begin{array}{l}\text { FOF }{ }^{\text {b }} \\
n(\%)\end{array}$ & $\begin{array}{c}\text { NFOF } \\
n(\%)\end{array}$ & $\mathbf{P}^{\mathbf{d}}$ \\
\hline Sex & & & \\
\hline Male $^{h}$ & $200(74.34)$ & $961(83.34)$ & $<0.01$ \\
\hline Female & $69(25.26)$ & $192(16.65)$ & \\
\hline Age (years) & & & $<0.01$ \\
\hline$<25$ & $23(8.55)$ & $195(16.91)$ & \\
\hline $25-34$ & $62(23.04)$ & $358(31.04)$ & \\
\hline $35-44^{h}$ & $73(27.13)$ & $277(24.02)$ & \\
\hline $45-54$ & $58(21.56)$ & $204(17.69)$ & \\
\hline$>54$ & $53(19.7)$ & $119(10.32)$ & \\
\hline Occupation $^{e}$ & & & $<0.01$ \\
\hline $\begin{array}{l}\text { Skilled non-manual } \\
\text { workers }\end{array}$ & $48(17.84)$ & $63(5.46)$ & \\
\hline Semi-skilled and & $46(17.1)$ & $100(8.67)$ & \\
\hline $\begin{array}{l}\text { unskilled non-manual } \\
\text { workers }\end{array}$ & $175(65.04)$ & $990(85.86)$ & \\
\hline
\end{tabular}




\begin{tabular}{|c|c|c|c|}
\hline Manual workers & & & \\
\hline Job tenure (months) & & & $<0.01$ \\
\hline $0-6^{h}$ & $184(68.4)$ & $480(41.63)$ & \\
\hline $7-12$ & $16(5.94)$ & $155(13.44)$ & \\
\hline $13-36$ & $27(10.04)$ & $215(18.64)$ & \\
\hline $36-60$ & $7(2.6)$ & $74(6.41)$ & \\
\hline$>60$ & $35(13.01)$ & $229(19.86)$ & \\
\hline \multicolumn{3}{|c|}{ Type of contract of employment } & $<0.01$ \\
\hline Permanent & $62(23.04)$ & $438(37.98)$ & \\
\hline Temporary ${ }^{h}$ & $204(75.83)$ & $620(53.77)$ & \\
\hline Other & $3(1.11)$ & $95(8.23)$ & \\
\hline \multicolumn{3}{|c|}{ Company size (utilization $>=83 \%$ ) } & $<0.01$ \\
\hline$\leq 150$ workers ${ }^{h}$ & $175(65.05)$ & $803(69.64)$ & \\
\hline$>150$ workers & $94(34.9)$ & $350(30.35)$ & \\
\hline Economic activity & & & $<0.01$ \\
\hline $\begin{array}{c}\text { Agriculture and } \\
\text { packaging } \\
\text { Industry }^{\boldsymbol{h}} \\
\text { Construction } \\
\text { Services }\end{array}$ & $\begin{array}{l}50(18.58) \\
96(35.68) \\
54(20.07) \\
69(25.65)\end{array}$ & $\mid \begin{array}{cc}94 & (8.15) \\
307 & (26.62) \\
330 & (28.62) \\
\mathbf{4 2 2} & (\mathbf{3 8 . 3 3})\end{array}$ & \\
\hline Job & & & $<0.01$ \\
\hline $\begin{array}{c}\text { Usual }^{h} \\
\text { Atypical }^{f}\end{array}$ & $\begin{array}{c}238(\mathbf{8 8 . 4 7 )} \\
31(11.52)\end{array}$ & $\begin{array}{c}1090 \\
(\mathbf{9 4 . 5 3 )} \\
63(5.46)\end{array}$ & \\
\hline $\begin{array}{c}\text { Workplace (5'S) } \\
\text { Principles }\end{array}$ & & & $<0.01$ \\
\hline Usual $^{h}$ & $186(69.14)$ & $995(86.29)$ & \\
\hline Atypical ${ }^{\mathrm{g}}$ & $83(30.85)$ & $158(13.7)$ & \\
\hline $\begin{array}{c}\text { Over Time Work shift } \\
\text { hour }\end{array}$ & & & $<0.01$ \\
\hline$<1.5 \mathrm{~h}$ & $58(21.56)$ & $364(31.56)$ & \\
\hline $1.5-2 h^{h}$ & $128(47.58)$ & $583(50.56)$ & \\
\hline$>2 \mathrm{~h}$ & $83(30.85)$ & $206(17.86)$ & \\
\hline Time during one shift & & & $<0.01$ \\
\hline 08-11 h (morning) & $27(10.03)$ & $222(19.25)$ & \\
\hline 11-01 h (afternoon) & $29(10.78)$ & $138(11.96)$ & \\
\hline 01-02 h (afternoon) ${ }^{h}$ & $166(61.71)$ & $571(49.52)$ & \\
\hline 02-04 h (night) & $47(17.47)$ & $252(21.85)$ & \\
\hline Week day & & & 0.04 \\
\hline Saturday & $41(15.24)$ & $130(11.27)$ & \\
\hline
\end{tabular}




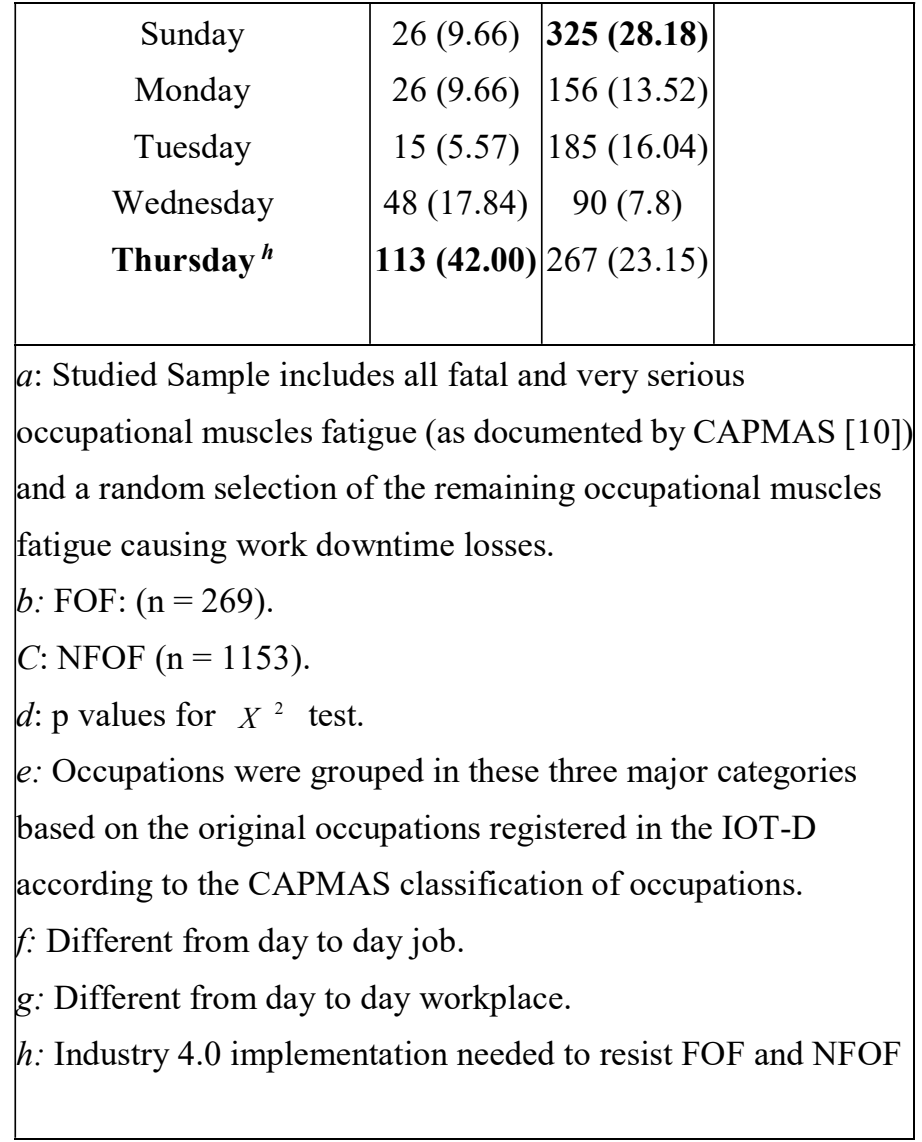

Table 2: (Industry 4.0) priority implementation for

Occupational characteristics in a sample of workers suffering occupational fatigue in Egypt, $2019(n=1422)^{a}$. [7]

\begin{tabular}{|c|c|c|c|}
\hline & $\begin{array}{l}\text { FOF }^{\text {b }} \\
n(\%)\end{array}$ & $\begin{array}{c}\text { NFOF }^{c} \\
n(\%)\end{array}$ & $P^{d}$ \\
\hline $\begin{array}{l}\text { Mechanism of } \\
\text { production }\end{array}$ & & & $<0.01$ \\
\hline $\begin{array}{c}\text { Rickety } \\
\text { Strike } \\
\text { Overstrain }^{h} \\
\text { Harmful substances } \\
\text { Natural causes }{ }^{\mathrm{f}} \\
\text { Other }\end{array}$ & $\begin{array}{c}36(13.38) \\
\mathbf{1 1 4}(\mathbf{4 2 . 3 7 )} \\
57(21.18) \\
14(5.2) \\
16(5.94) \\
32(11.89)\end{array}$ & $\mid \begin{array}{c}89(7.7) \\
392(33.99) \\
485(\mathbf{4 2 . 0 6}) \\
139(12.05) \\
22(1.9) \\
26(2.25)\end{array}$ & $\begin{array}{c}0.07 \\
0.66 \\
<0.01 \\
0.18 \\
0.01 \\
<0.01\end{array}$ \\
\hline \multicolumn{3}{|c|}{ Involved agent (5'S) Principles } & $<0.01$ \\
\hline $\begin{array}{c}\text { Noise, lighting and others } \\
\text { Movable devices }\end{array}$ & $20(7.43)$ & $101(8.75)$ & $\begin{array}{c}0.14 \\
<0.01\end{array}$ \\
\hline Worker self confidence & $31(11.52)$ & $208(18.03)$ & $<0.01$ \\
\hline
\end{tabular}




\begin{tabular}{|c|c|c|c|}
\hline Defective Tools and & 84 (31.22) & $68(5.89)$ & $<0.01$ \\
\hline equipment $^{h}$ & $52(19.33)$ & $329(28.53)$ & 0.01 \\
\hline Wrong Devices location & $62(23.04)$ & $296(25.67)$ & 0.07 \\
\hline$h$ & $14(5.2)$ & $118(10.23)$ & 0.58 \\
\hline Engines & $6(2.2)$ & $33(2.86)$ & \\
\hline Other & & & \\
\hline fatigued worker & & & $<0.01$ \\
\hline & $27(10.03)$ & & \\
\hline & $13(483)$ & $157(13.6)$ & $<0.01$ \\
\hline Trunk & ) (דנס) 10. & $211(18.3)$ & $<0.01$ \\
\hline Terminals & $2(0.145)$ & 755 (65.48) & $<0.01$ \\
\hline Internal organs & & $30(2.6)$ & $<0.01$ \\
\hline$a$ : Categories as documen & ted in the Eg & yptian FOF & NFOF \\
\hline $\begin{array}{l}\text { Notification Form and in } \\
\text { analysis. }\end{array}$ & the correspor & nding IOT-D & ed in this \\
\hline c: FOF: fatal occupationa & 1 fatigue $(n=$ & 269). & \\
\hline$b$ : Sample of FOF and NF & OF (as docu & mented at $\mathrm{C}$ & MAS [10]) \\
\hline and a random selection of & the remainin & ng occupatio & fatigue \\
\hline causing at least 1 day of 1 & osses from $w$ & ork. & \\
\hline$C:$ FOF: fatal occupationa & l fatigue $(n=$ & $=269)$. & \\
\hline$d:$ NFOF: non-fatal occup & pational fatig & ue $(n=1153$ & \\
\hline$e: \mathrm{p}$ values for $X^{2}$ test. & & & \\
\hline e: Occupations were grou & ped in these & three major & egories \\
\hline based on the original occu & upations regis & stered in the & T-D \\
\hline according to the Egyptian & Social Secur & rity Adminis & tion \\
\hline classification of occupatio & & & \\
\hline$g$ : Different from everyda & y workplace. & & \\
\hline$h$ : Industry 4.0 implement & tation needed & to resist FO & and NFOF \\
\hline
\end{tabular}

Table 3: (Industry 4.0) priority implementation

adjusted odds ratio $99 \%$ confidence intervals

(99\% CI) for occupational factors related to

occupational fatigue ${ }^{a}$.

\begin{tabular}{|c|c|c|c|c|}
\hline & Cases & $\begin{array}{c}\text { Control } \\
\mathbf{s}^{\mathbf{c}}\end{array}$ & $\mathbf{9 9 \%} \mathbf{C I}$ & $\mathbf{P}$ \\
\hline Sex & & & & \\
Male & $\mathbf{2 0 0}$ & $\mathbf{9 6 1}$ & $10.92(4.80-24$ & \\
Female & 69 & 192 & $84)$ & $<0.0$ \\
& & & 1 & 1 \\
\hline
\end{tabular}




\begin{tabular}{|c|c|c|c|c|}
\hline Age (years) & & & & $\begin{array}{c}<0.0 \\
1\end{array}$ \\
\hline & \multirow[b]{3}{*}{21} & \multirow[b]{3}{*}{198} & 1 & \\
\hline & & & 1.72 & \\
\hline$<25$ & & & $(1.19-2.49)$ & \\
\hline $25-34$ & 69 & 340 & 2.42 & \\
\hline $35-44^{h}$ & 91 & 287 & $(1.68-3.50)$ & \\
\hline $45-54$ & 53 & 288 & 2.64 & \\
\hline \multirow[t]{3}{*}{$>54$} & \multirow[t]{3}{*}{35} & \multirow[t]{3}{*}{117} & $(1.81-3.88)$ & \\
\hline & & & 3.44 & \\
\hline & & & $(2.27-5.21)$ & \\
\hline \multirow{2}{*}{$\begin{array}{c}\text { Economic } \\
\text { activity }\end{array}$} & & & & $<0.0$ \\
\hline & & & & 1 \\
\hline & \multirow[b]{2}{*}{37} & \multirow[b]{2}{*}{90} & 1 & \\
\hline Services & & & 2.69 & \\
\hline \multirow{3}{*}{$\begin{array}{c}\text { Agriculture and } \\
\text { fishing } \\
\text { Industry }^{h}\end{array}$} & \multirow[t]{2}{*}{62} & \multirow[t]{2}{*}{319} & $(1.91-3.79)$ & \\
\hline & & & 0.94 & \\
\hline & 103 & 333 & $(0.72-1.24)$ & \\
\hline \multirow[t]{2}{*}{ Construction } & \multirow[t]{2}{*}{67} & \multirow[t]{2}{*}{409} & 1.36 & \\
\hline & & & $(1.05-1.76)$ & \\
\hline \multirow{2}{*}{$\begin{array}{l}\text { Job (5'S) } \\
\text { Principles }\end{array}$} & & & & $<0.0$ \\
\hline & & & & 1 \\
\hline \multirow{2}{*}{ Usual $^{h}$} & 254 & \multirow{2}{*}{1129} & 1 & \\
\hline & \multirow{2}{*}{14} & & 2.08 & \\
\hline Atypical & & 24 & $(1.27-3.39)$ & \\
\hline \multicolumn{3}{|c|}{ Workplace (5'S) Principles } & $<0.01$ & \\
\hline \multirow{3}{*}{$\begin{array}{l}\text { Usual }^{\boldsymbol{h}} \\
\text { Atypical }\end{array}$} & 193 & 1026 & 1 & \\
\hline & \multirow{2}{*}{76} & \multirow{2}{*}{126} & & \\
\hline & & & $(2.27-3.59)$ & \\
\hline Over Time W & k shi & hour & & $<0.0$ \\
\hline & & & 1 & \\
\hline$<1.5 \mathrm{~h}$ & 69 & 380 & 1.25 & \\
\hline $1.5-2 h^{h}$ & 139 & 562 & $(1.00-1.57)$ & \\
\hline$>2 \mathrm{~h}$ & 61 & 209 & 1.44 & \\
\hline & & & $(1.10-1.90)$ & \\
\hline Type of contrac & f em & ymen & & \\
\hline Permanent & 113 & 449 & 1 & $<0.0$ \\
\hline Temporary $^{h}$ & 151 & 622 & $5.18(2.63-10.1$ & 1 \\
\hline Other & 5 & 82 & 8) & \\
\hline
\end{tabular}



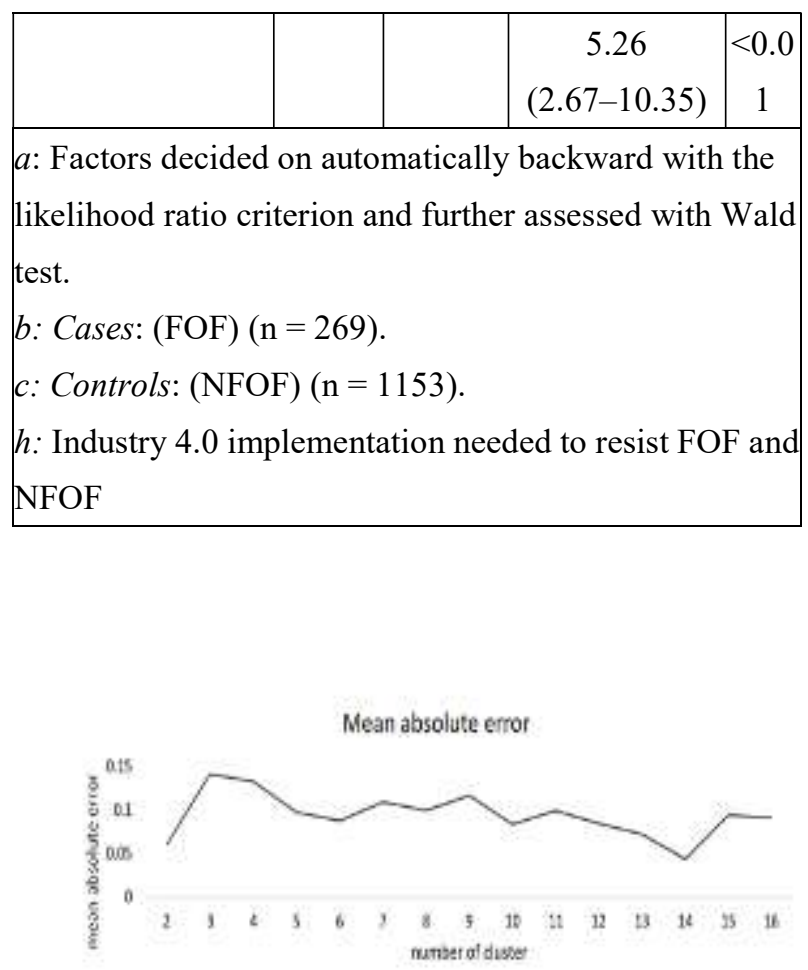

\author{
Figure 7: Absolute error between real and \\ predicted profile according to the \# of \\ clusters
}

\title{
8. CONCLUSIONS
}

This study guides to enabling the provision the optimum usage of modern Industry 4.0 tools to mitigate the negative effects of occupational fatigue. Also, identify the beneficiaries to use these tools. The main conclusion from this analysis show that the losses of a fatal consequence of occupational fatigue $\|$ down times continuo increases proportionally with age of male and work shift time of temporary workers if compared with permanent workers, on the other hand it give us mirror to contribute industry 4.0 technologies to avoid FOF and NFOF. Workers in industry, construction, and job shop economic sectors are at higher losses too. Any workplaces have atypical jobs are positive determinants of fatal outcomes. Besides, main mechanisms related to fatal outcomes include strike and movable devices are frequently involved. The whole analysis system is run for fifteen times, and the error is calculated using 10-fold cross validation. The optimal number of clusters $\mathrm{k}^{*}$ for the analysed data was estimated to be fourteen, as shown in Figure 7.

Table 4 shows the number of workers included in each cluster taking into account the behavioural actions aims to reduce the downtime and defects, and their mean absolute error (MAE). Figure 8 illustrates some examples of clusters that have the maximum error. The study recommends that the permanent control of the behaviour of workers in middle age, and reduce manual workers, which cause $88 \%$ of the problems. As well as every 5 years for promotion and assignment of tasks associated with the previous tasks. 


\begin{tabular}{|c|c|c|c|c|c|c|c|c|c|c|c|c|c|c|}
\hline duter & 0 & 1 & 1 & 3 & 4 & 5 & 6 & 7 & 1 & 9 & $D$ & 11 & 12 & 13 \\
\hline Dorn & 13 & 13 & 17 & 1 & $\theta$ & 23 & 1 & $n$ & 3 & 17 & 12 & 33 & $y$ & 18 \\
\hline
\end{tabular}

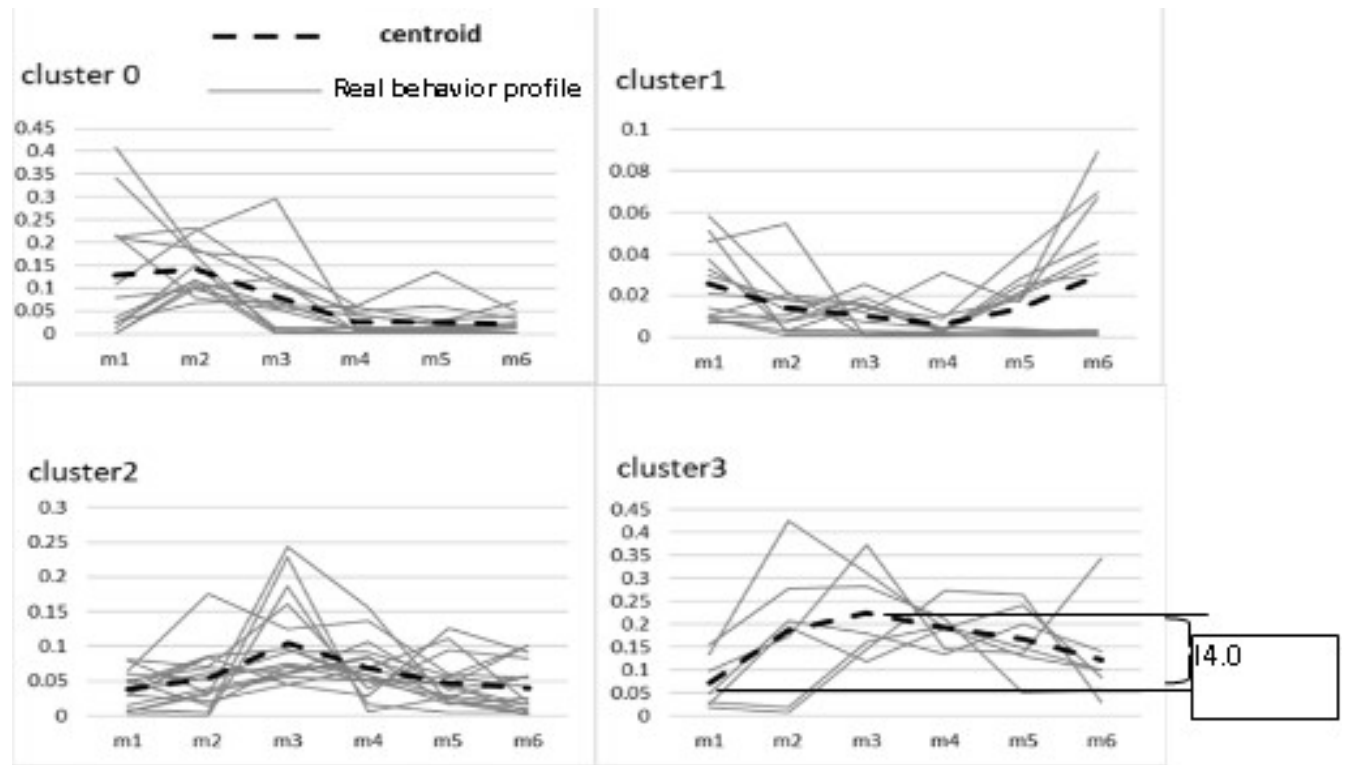

Figure 8: Examples of occupational fatigue downtime behavioral profile

The heights of profile represent the needing of industry 4.0 contribution to reduce the occupational fatigue downtime, this contribution reduce the downtime and defects and increase the safety.

The study also advises daily renewal in the nature of the work to prevent the $20 \%$ of the problems leading to occupational fatigue, because of boredom and excessive self-confidence, which generate $97 \%$ of the problems. And the employer not to be forced to extra time more than once an hour and there is strict control between the $1.00 \mathrm{pm}$ and $2.00 \mathrm{pm}$, to avoid 50\% of errors. In addition, increases the employer's good news and encouraging working or resting periods on Sunday and reduce the fitness muscles on the weekends of each week with the ideal arrangement for machinery and the application of the philosophies that reduce errors and reduce problems by $21 \%$ and $14 \%$ respectively. The main purpose of the research is to draw attention to annex the occupational fatigue to the list of waste, which dealt with Lean philosophy. Table- 5 shows the comparison between (as-is) situation and (To-be) and illustrates the contribution level of industry 4.0 to reduce the occupational fatigue downtime.

Table 5: The comparison between (as-is) and (To-be) model in industry 4.0 contribution

\begin{tabular}{|l|l|c|}
\hline & As-is & $\begin{array}{c}\text { To-be } \\
\text { after } \\
\text { COFC }\end{array}$ \\
\hline Correctly classified \% & 14 & 79 \\
\hline
\end{tabular}




\begin{tabular}{|l|l|l|}
\hline MAE & 0.1219 & 0.0435 \\
\hline RMSE & 0.2979 & 0.157 \\
\hline Relative absolute error \% & 94 & 33 \\
\hline \# of rules & 64 & 16 \\
\hline Size of tree & 116 & $\#$ \\
\hline Industry 4.0 contribution \% & $>86$ & $<21$ \\
\hline
\end{tabular}

The constrained clustering is excellence on traditional k-means due to intervenes the industry 4.0 thinking as shown in Table-6.

Table 6: comparison between k-means and constrained occupational fatigue losses cluster

\begin{tabular}{|l|l|l|}
\hline & k-means & COFLC \\
\hline Minimum cluster size violation & 3 & ------ \\
\hline Must-link violation & 24 & 7 \\
\hline Cannot-link violation & 11 & 1 \\
\hline
\end{tabular}

\section{RECOMMENDATIONS}

It's preferred for investments that depends on the muscles of workers in their work to:

- $\quad$ Reduce the manual workers between 35-44 old years using more usable industry 4.0 equipment and developed their tools.

- Consumes the first 6 months of work in training on modern industry 4.0 tools, and become under supervisors control

- $\quad$ Reduce the temporary workers and firing action to gain the loyalty of workers

- Must make a change in our seen for the place of work or job description and communications

- $\quad$ Its forbidden to increase the overtime than $1.5 \mathrm{~h}$

- The workers must take rest time, preferably between $1.00 \mathrm{pm}: 2.00 \mathrm{pm}$, daily or no fitness work

- The number of shift hours must be shrinkable on Thursday

Create a commitment of implementing 5'S procedures in the place and sustain in evaluation.

\section{AUTHOR CONTRIBUTIONS}

Conceptualization, A.M.A. and S.E.; methodology, A.M.A. and S.E.; validation, A.M.A.;

formal analysis, A.M.A.; investigation, S.E.; resources, A.M.A.; data curation, A.M.A., S.E.; writing-original draft preparation, A.M.A.and S.E.,; writing - review and editing, S.E.; supervision, A.M.A.; project administration, A.M.A. and S.E.; software A.M.A 
All authors have read and agreed to the published version of the manuscript.

Funding: This research was funded by the Deanship of Scientific Research at Princess Nourah bint Abdulrahman University through the Fast-track Research Funding Program. The work reported in this article has been conducted while some of the researchers are affiliated with Princess Nourah bint Abdulrahman University.

\section{REFERENCES}

1. A., Bhattacherjee, N., Chau, C., Otero, B., Legras, Benamghar, L., Michaely, J.P., et al., Relationships of job and some individual characteristics to occupational fatigue in employed people: a community-based study. J. Occup. Health 45, 382-391, 2003.

2. A.M. Feyer, A.M. Williamson, N. Stout, T. Driscoll, Usher, H., J.D. Langley, , 2001. Comparison of work related fatal fatigue in the United States, Australia, and New Zealand: method and overall findings. Inj. Prev. 7, 22-28.

3. B. Bonnechère, B. Jansen, P. Salvia, H. Bouzahouene, V. Sholukha, J. Cornelis, M. Rooze \& S. Van Sint Jan, (2014).

"Determination of the precision and accuracy of morphological measurements using the Kinect ${ }^{\mathrm{TM}}$ sensor": Comparison with standard stereophotogrammetry. Ergonomics, 57, 622-631.

4. B. Thacker and J. MacKenzie, Preface: The Role of the Epidemiologist in Injury Prevention and Control-An Unmet Challenge. Vol. 25, 2003. DOI: 10.1093/epirev/mxg008.

5. E. Castejion, X. Crespan, 2005. Downtimes de treball: el per què de tot plegat [Occupational Fatigue : Their Overall Reasons]. Enginyers Industrials de Catalunya, Barcelona.

6. Egyptian Commission, 2015. Work and Health in the EG. A Statistical Portrait. Office for Official Publications of the Egyptian Communities, 12 June 2015 at 3.00 PM Cairo.

http://www.capmas.gov.eg/Pages/Http404ErrorPage.aspx?aspxerrorpath=/default.aspx

7. F.G., Benavides, G.L., Delclos, S.P., Cooper, J., Benach, 2003a. Comparison of fatal occupational fatigue surveillance systems between the European Union and the United States. Am. J. Ind. Med. 44, 385-391.

8. F.G., Benavides, J., Benach, C., Muntaner, G.L., Delclos, Catot, N., Amable, M., Associations between temporary employment and occupational fatigue: what are the mechanisms? Occup. Environ. Med. 63, 416-421, 2006. Cited 10 July 2014, .

http://www.bt.cdc.gov/masscasualties/explosions.asp

9. G.C., Gauchard, N., Chau, C., Touron, L., Benamghar, D., Dehaene, Perrin, Ph.P., et al., 2003. Individual characteristics in occupational downtimes due to imbalance: a case-control study of the employees of a railway company. Occup. Environ. Med. 60, 330-335.

10. Hosmer, W. David; Lemeshow, Stanley (2013). Applied Logistic Regression. New York: Wiley. ISBN 978-0-470-58247-3.

11. L. Artieda, "Los cambios en la notificaci $\square n$ de accidentes de trabajo y sus efectosen el sistema de informaci $\square$ " [changes in the notification of occupational downtimes and their effects on the information system]. Arch. Prev. Riesgos Worker. 7, 49-52, 2004.

12. M., Hagberg, D., Christiani, T.K., Courtney, W., Halperin, T.B., Leamon, T.J., Smith, 1997. Conceptual and definitional issues in occupational fatigue epidemiology. 
13. M. A. Hernandez, \& L. A. Peterson, (2012). Work-Related Musculoskeletal Disorders and Pain. Handbook of Occupational Health and Wellness, Springer US, 63-86.

14. N. Chau, J.M. Mur, L. Benamghar, C.Siegfried, J.L. Dangelzer, , Franc, M. ais, , et al., 2004. Relationships between certain individual characteristics and occupational fatigue for various jobs in the construction industry: a case-control study. Am. J. Ind. Med. 45, 84-92.

15. R. Blumenthal (2012b), 'Secondary missile injury from lightning strike', The American Journal of Forensic Medicine and Pathology, vol. 33, no. 1, March, pp. 83 - 85.

16. S., Folkard, P., Tucker, 2003. Shift work, safety and productivity. Occup. Med. 53, 95-101.

17. The Data \& Analysis Section, Safe Work Australia, October (2013). work related injuries and fatalities involving a fall from height, Australia.: Wiley. ISBN 978-1-74361-187-6.

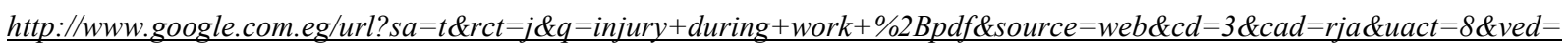
OCDYQFjACahUKEwiftfWQ187HAhWtB9sKHTJ5Da4\&url=http\%3A\%2F\%2Fwww.safeworkaustralia.gov.au\%2Fsites\%2FS WA\%2Fabout\%2FPublications $\% 2$ FDocuments $\% 2 F 812 \% 2$ FFalls-from-Height.pdf\&ei $=k \operatorname{tnh} V Z-k B a 2 P 7 A a y 8 r X w C g \& u s g=A F$ QjCNHIfIDES6 TV4GOJCYIKTz8 BZKNQ

18. Demiriz, "Demand classification based on pairwise worker skills associations," Procedia Comput. Sci., vol. 36, no. C, pp. 261-268, 2014.

19. S. Thomassey and A. Fiordaliso, "A hybrid sales classification system based on clustering and decision trees," Decis. Support Syst., vol. 42, no. 1, pp. 408-421, 2006. 